\title{
Traditio Legis y otras representaciones iconográficas a través de objetos de vidrio y vidriados
}

\author{
Juan Carlos Olivera Delgado \\ Universidad de Córdoba
}

\begin{abstract}
Resumen: En el presente artículo analizaremos las patenas de vidrio y vidriadas decoradas con la imagen de Cristo, san Pedro y san Pablo, así como el programa iconográfico de la Traditio Legis. A pesar de que no son muy numerosas en España, sí contamos con el importante testimonio de Cástulo (Linares, Jaén) o de la Almoina (Valencia). El análisis de sus formas intrínsecas nos aporta una valiosa información iconográfica, que sería la antesala del Pantocrator representado en el arte Románico en siglos posteriores.
\end{abstract}

Palabras claves: Cristo, iconografía, vidrio romano, arte paleocristiano.

\begin{abstract}
In the present article we will analyze the glazed patens decorated with the iconographic program Traditio Legis in Spain, although they are not very numerous, if we count on the important testimony of Cástulo (Linares, Jaén) or of the Almoina (Valencia). The analysis of its intrinsic forms gives us a valuable iconographic information, which would be the ante-room of the Pantocrator represented in Romanesque art centuries later.
\end{abstract}

Keys words: Christ, iconography, roman glass, paleochristian art.

\section{INTRODUCCIÓN}

La iconografía de Cristo es probablemente una de las más representadas a lo largo de la historia. Esto aporta un carácter enriquecedor ya que no siempre se utilizaron los mismos atributos para realizar su imagen. Las primeras surgieron entorno al siglo III y fueron realizadas en las catacumbas romanas debido a la persecución de la fe cristiana. Se trata de pinturas murales destacando las de santa Domitila, san Marcelino y san Pedro o san Calixto.

Fecha de recepción: 9 de enero de 2019

Fecha de aceptación y versión final: 4 de mayo de 2019

https://doi.org/10.46543/ISID.1928.1004 I ISSN: 1131-7027 I ISSN-e: 2660-7743 
Posteriormente con la legitimación del cristianismo, su imagen asumió claramente la influencia imperial. Los romanos tomaron de los griegos, entre otras, su representación mitológica. Posteriormente, la iglesia primitiva asimiló la concepción y representación del poder teocrático con fundamentación en los textos bíblicos y supremacía sobre los hombres, algo que se extenderá a lo largo de la Edad Media, el Renacimiento y el mundo Moderno. ${ }^{1}$ La doctrina de la Iglesia sobre la representación de Cristo se remonta a los siglos IV y v, una vez que los concilios de Nicea (325), Éfeso (431) y Calcedonia (451) promulgaron que Cristo es Dios y hombre verdadero y que ambas naturalezas confluyen en un mismo ser, que posibilitó la representación iconográfica de Cristo. ${ }^{2}$

La utilización del vidrio durante los primeros siglos del cristianismo es patente. Existían ventanas vidriadas decoradas desde época muy temprana, como bien describió Prudencio, al hablar sobre Constantinopla:"Bajo los redondeados arcos de las ventanas de la basílica brillaba el vidrio en innumerables colores". Los vidrios postromanos presentan menor diversidad en sus formas y decoraciones, al tener menos maestría en la consecución del color. ${ }^{3}$ La variedad de vidrios tardíos no es muy numerosa, centrándose en la producción de cuencos o vasos, siendo a partir del siglo IV cuando aparezcan los cuencos troncocónicos, ${ }^{4}$ como es el caso procedente de la Almoina (Valencia).

Los objetos de vidrio para la liturgia eran ya utilizados entre los siglos II y III como recoge el Liber Pontificalis, durante el papado de Ceferino (199-217): "Et fecit constitutum de ecclesia, et patenas uitreas ante sacerdotes in ecclesia, et ministros supportantes". Esta producción parece llegar hasta el siglo v, comenzando a desaparecer en el siglo vi. ${ }^{5}$

El estudio de los vidrios y de los objetos vidriados romanos no tiene un gran recorrido en nuestro país. Los primeros estudios datan del siglo pasado, siendo el primer trabajo el del profesor Vigil Pascual (1969). ${ }^{6}$ No ocurre lo mismo en el ámbito académico internacional, donde existen dos focos de estudios importantes: Nueva York y Lieja. Destaca Journal Glass, que surgió a partir del Corning Museum y que cuenta con una de las mayores exposiciones mundiales

1 Cf. José Martínez GÁzQuez, "Memoria de la Maiestas Domini del Mundo Clásico a la Edad Media", Cuadernos del CEMYR 24 (2016) 31-50.

2 Cf. Fermín Labarba García, “El rostro de Cristo en el arte”, Anuario de historia de la Iglesia 25 (2016) 269 (265-316).

3 Cf. Eduardo Alonso Cereza, El vidrio romano en los museos de Madrid, Tesis de la Universidad Complutense de Madrid, Facultad de Geografía e Historia, Departamento de Historia del Arte I, Madrid, 2010, 119 < https://eprints.ucm.es/10625/1/T31874.pdf> [consultada: 10 de mayo de 2019].

4 Cf. Sarah Dahí ElenA, "Vidrios de los siglos IV-V D.C. procedentes del yacimiento de la Viña de la Iglesia (Sotoserrano, Salamanca)", Zephyrus: Revista de prehistoria y arqueología 66 (2010) 221 (219-226)

5 Cf. Dahí Elena, "Vidrios", 222.

6 Cf. Marcelo Vigil Pascual, El vidrio en el mundo antiguo, Instituto Español de Arqueología, Consejo Superior de Investigaciones Científicas, Madrid, 1969. 
dedicadas al vidrio en todas las épocas (con gran variedad de material tardo romano cristiano, vasijas, platos, ánforas...). Más tarde, se constituyó en Lieja la Journées Internationales duVerre bajo la dirección de Joseph Phillippe (1956) que actualmente se llama Association Internationale pour L'Histoire du Verre (AIHV).

No existe un gran número de estudios propiamente cristianos, si bien es cierto que la mayor parte de trabajos sobre vidrios romanos simplemente mencionan la variedad tardo antigua cristiana y no se detienen en analizar sus formas intrínsecas. El gran estudio de vidrios de la RAH (2005) no llega a mencionar esta cuestión, debido a que es un estudio solamente de los vidrios que posee. Cabe destacar la exposición: "La fragilidad en el tiempo. El vidrio en la antigüedad tardía", realizada por el Museu d'Arqueologia de Catalunya, (17-092005/26-02-2006), dentro del proyecto de la Unión Europea Glassway: El vidrio desde la antigüedad tardía a la actualidad en la cuenca del Mediterráneo bajo el programa Interreg III B Mediterráneo occidental, así como la tesis doctoral sobre los vidrios de la Comunidad de Madrid realizado por Alonso Cereza (2010), donde dedica un capítulo a los vidrios paleocristianos.

Hay dos modalidades en cuanto a su fabricación: de vidrio o vidriados. La primera atiende a los objetos realizados solo y exclusivamente con dicho material. La segunda es realizada con otros materiales, principalmente arcilla, aplicando una fina capa de cristal en su superficie, dando un aspecto vidriado y más luminoso. A ambas tipologías se les puede aplicar pigmentos en su superficie, con el fin de dibujar representaciones principalmente de tema religioso.

Este ensayo pretende hacer un análisis de la representación de Cristo junto a san Pedro y san Pablo, haciendo hincapié en la Traditio Legis a partir de los objetos con dicha decoración, realizando un estudio iconográfico de la misma.

\section{LA TRADITIO LEGIS}

La Traditio Legis, o entregar la Ley, es la denominación iconográfica que define a la representación de Cristo entregando la ley divina a san Pedro. Esta imagen suele estar acompañada de san Pedro o de algún otro discípulo, como testigo del acto simbólico de la transmisión del mensaje de salvación evangélica. El cristianismo, como continuador del arte romano, tomó esta representación de la tradición imperial, en la que el emperador hacia entrega de un rollo (que generalmente eran leyes o algún privilegio), a alguien de su entorno o confianza. ${ }^{7}$ Los orígenes suelen fijarse en el siglo iv y no en fechas anteriores. Existen ejemplos de esta representación en otras artes plásticas, destacando los del baptisterio

7 Cf. Matthias Exner, "Estucos”, en Enrico CAstelnuovo - Giuseppe SERGI (eds.), Arte e Historia en la Edad Media. II: Del construir: técnicas, artistas, artesanos, comitentes, Madrid, Akal, 2013, 517-518. 
de san Giovanni in Fonte (Nápoles), ${ }^{8}$ el mausoleo de santa Constanza (Roma), un fragmento en la catacumba de san Sebastián (Roma) o el sarcófago de Junio Basso (Museos Vaticanos).

Hay ciertos atributos que componen la Traditio Legis, como son la Maiestas et Gloria, el poder de Cristo como Dominus o Rex y su sabiduría infinita Sapientae, que se pueden observar en el Antiguo Testamento. Así, en Génesis 1,1 ("Al principio creo Dios el cielo y la tierra") se aprecia el carácter divino del Dios creador y hacedor de todas las cosas; el Salmo 18,13 ("Al fulgor de su presencia, las nubes se deshicieron en granizo y centellas") muestra la magnificencia de Dios omnipotente, que puede causar pavor; el Salmo 19,2 ("Los cielos proclaman la gloria de Dios") recoge un atributo muy utilizado en épocas posteriores para alabar a Dios y a Cristo; en el Salmo 93,1 ("El Señor es rey y está vestido y ceñido de poder") se presenta a Dios como rey del universo, todopoderoso; en Eclesiástico 1,1 ("Toda sabiduría viene del Señor") Dios es la sabiduría en sí misma y por tanto, fuente de toda sabiduría. Finalmente, en Isaías 54,5 ("No temas... Dios es tu Creador, su nombre es el Señor Todopoderoso") el Señor aparece como el omnipotente, creador y que todo lo puede.

El Nuevo Testamento señala también los atributos anteriormente mencionados, aunque ya haciendo referencia al Cordero de Dios o a Cristo. Así, en Apocalipsis 21, 23 ("Tampoco [Jerusalén] necesita sol ni luna, se iluminan con la Gloria de Dios y su antorcha es el Cordero") se proyecta al igual que en el ya mencionado Salmo 18,13 el carácter de magnificencia de Dios; en Efesios 6,5 ("Esclavos, obedeced a vuestros amos terrenos como si de Cristo se tratara") se presenta la imagen de Cristo como Domini, en la tierra. Muy revelador, entre otros, es la Carta a los Colosenses 1,15-20 ("Cristo es la imagen del Dios invisible... en él fueron creadas todas las cosas, tronos, dominaciones, principados y potestades..., él es el principio de todo, el primogénito de los que triunfan sobre la muerte, y por eso tiene primacía sobre todas las cosas"), en la que Cristo aparece como origen y razón de todo, de vida y muerte, de reinos y de toda criatura. Es sin duda, uno de los versículos más descriptivos de las características asociadas a la Traditio Legis.

\subsection{La patena de Cástulo}

La patena de vidrio de Cástulo es la prueba fehaciente de que existe una gran cantidad de material tardo antiguo cristiano que aún no se ha encontrado. Fue descubierta por el equipo de arqueólogos de Forum MMX en octubre de 2014 en un área del yacimiento conocida como área 2, en el denominado edificio E. Todo apunta a que dicho edificio tuvo funciones religiosas, pero aún no se han encontrado más evidencias de que se practicara la liturgia cristiana en él. Debido

8 En el que se puede leer: Dominus legem dat, escrito en el rollo que Cristo entrega a san Pedro. 


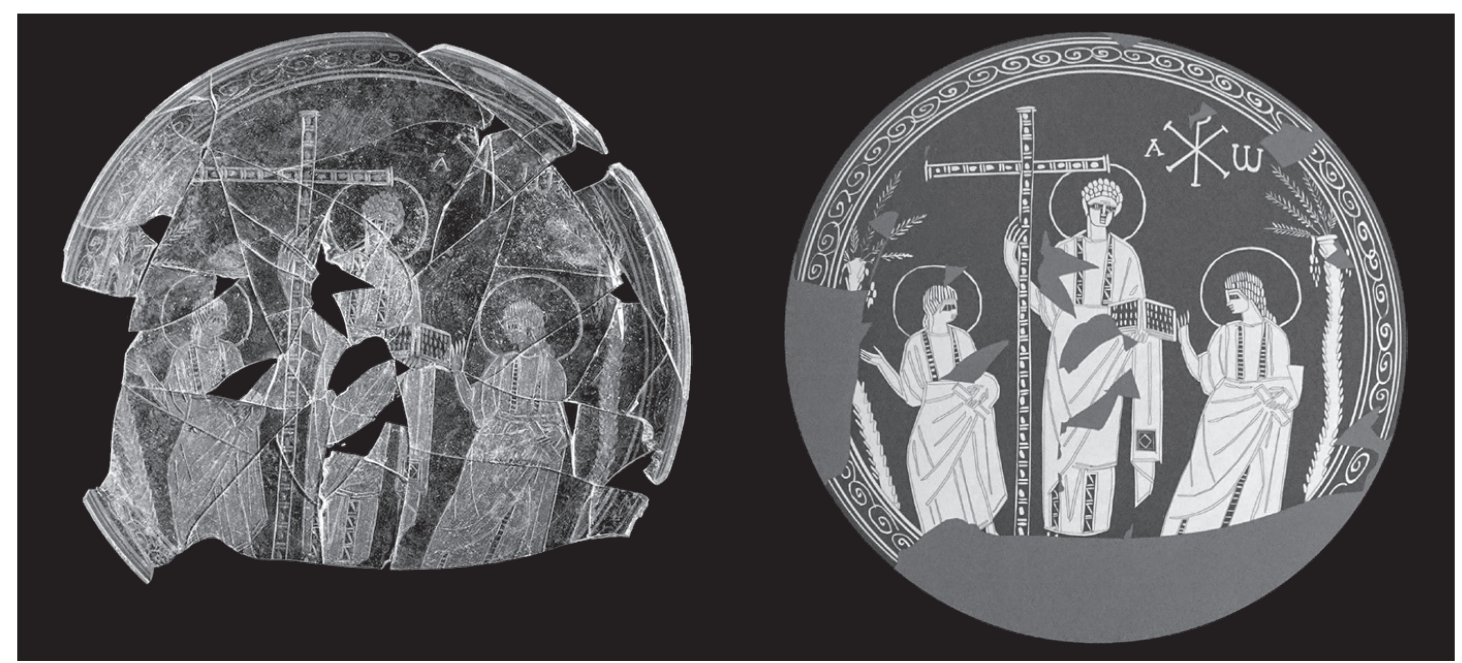

Imagen 1: Patena de Cástulo, en Concepción CHOClán SABINA - Marcelo CASTRO, "Museo Arqueológico de Linares-Monografía de Cástulo”, Boletín Arqueológico Nacional 35 (2007) 364.

a la importancia del hallazgo, este proyecto se incluyó en la AIHV (International Association for the History of Glass), cuyo congreso se celebró en Suiza del 7 al 11 de septiembre de 2015.

Con 22 centímetros de diámetro, 2 milímetros de espesor, 4 centímetros de altura y con apenas 175 gramos de vidrio verdoso, se conserva el 81\% de la pieza. ${ }^{9}$ Las formas intrínsecas de esta representación se deben analizar con atención ya que son de gran riqueza iconográfica, destacando los dos apóstoles, las palmeras, el crismón, la cruz gemada, y el rollo con las leyes, además de la vestimenta de los personajes.

Los personajes que acompañan a Cristo, según dijo el deán de la catedral de Jaén, Francisco Juan Martínez Rojas, no pueden identificarse con los apóstoles Pedro y Pablo porque nada así lo indica. ${ }^{10}$ Una de las características que hay que destacar es la aureola, atributo de santidad, además de los pergaminos o rotulus legis que ambos llevan.

Las palmeras, como símbolo de inmortalidad, representan el triunfo sobre la muerte y están asociadas desde antiguo a los mártires, a Cristo y a la Iglesia. ${ }^{11}$ El crismón representa a Cristo, con el anagrama de las letras griegas Xi y Rho, flanqueado también por las letras alfa y omega, principio y fin del alfabeto griego, adquiriendo la simbología de Cristo principio y fin de todo lo creado, de vida y muerte. ${ }^{12}$ La cruz gemada simboliza la resurrección de Cristo, vencedor de la muerte.

9 Cf. Concejalía de Turismo del Ayuntamiento de Linares, Cástulo la ciudad deseada, Linares, 2017, 17.

10 Cf. <https://elpais.com/ccaa/2014/10/01/andalucia/1412183783_270580.html>. [Consulta: 20 de mayo de 2019].

11 Cf. Ana Valtierra Lacalle, "La palmera y la palma. Adaptación medieval de una antigua iconografía", Revista digital de Iconografía Medieval vol. 9 n. 17 (2017) 105.

12 Cf. Francisco de Asís GARcía GARCíA, “El crismón”, Revista Digital de Iconografía Medieval, vol. 2, n. ${ }^{\circ} 3$ (2010) 21-31. 
La entrega por parte de Cristo del Evangelio o las leyes que deben seguir sus discípulos es la parte central del conjunto iconográfico. Los tres personajes visten una túnica griega o clásica, continuando con la tradición greco-romana del cristianismo primitivo. El color verdoso o con tonalidades azuladas de la vestimenta posee una simbología propia, que representa la dualidad entre la vida y la muerte al ser un color tenue y efímero al igual que el objeto realizado con este frágil material. ${ }^{13}$

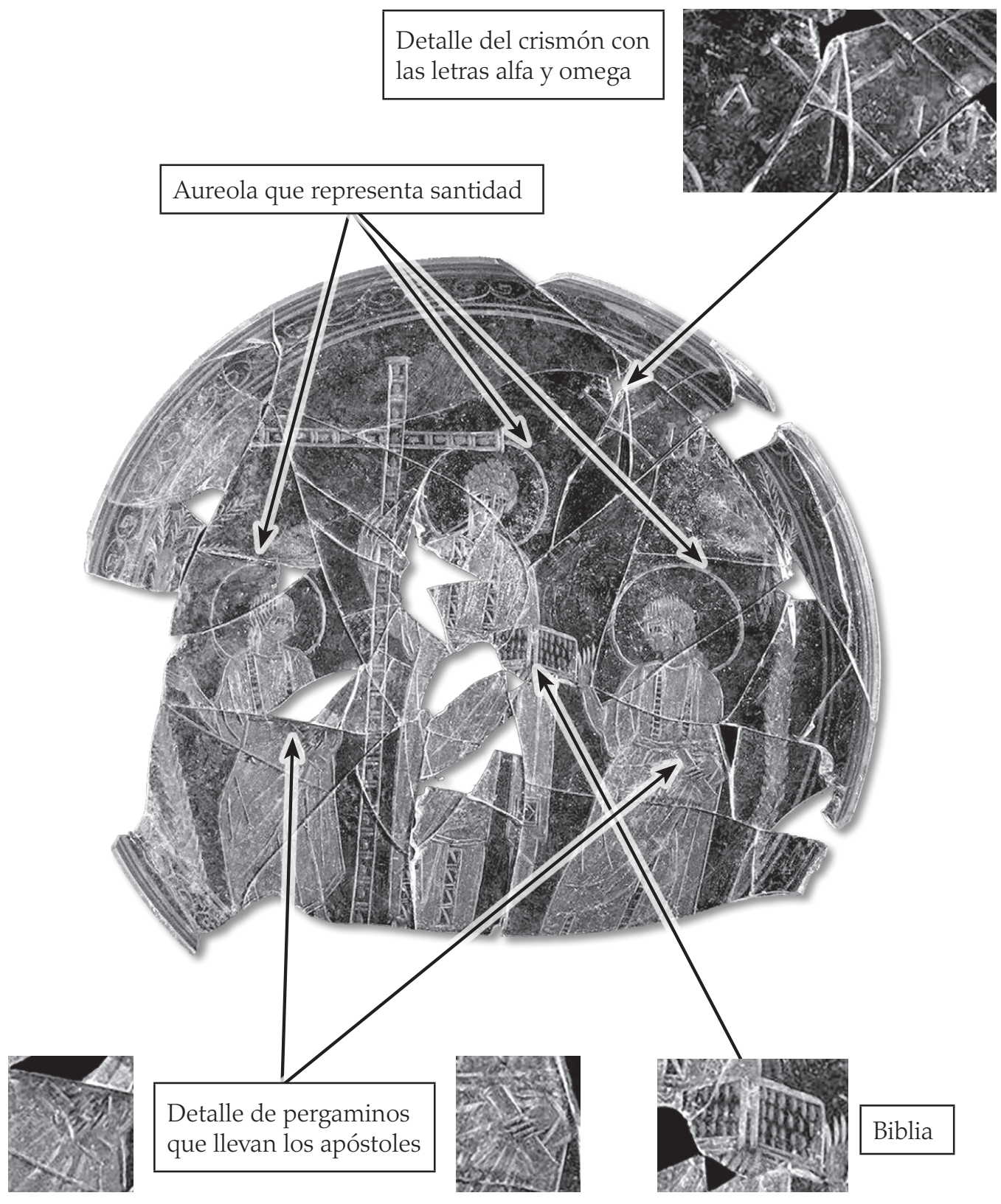

Imagen 2

13 Cf. Alonso Cereza, “Vidrio romano”, 143-145. 


\section{FORMAS COMPARATIVAS}

La imagen de Cristo al estilo de la Traditio Legis, fue muy usada a lo largo del siglo Iv continuando algunos ejemplos de similitud icónica durante el siglo v, como es el mosaico del mausoleo de la Gala Placidia (Rávena), donde se observa un Cristo joven, imberbe, vestido con toga de filósofo o a la manera clásica, sujetando la cruz con la mano izquierda y con la derecha un libro, posiblemente la Biblia o el Nuevo Testamento. Aunque en este caso hace referencia al Buen Pastor, la apariencia es similar:

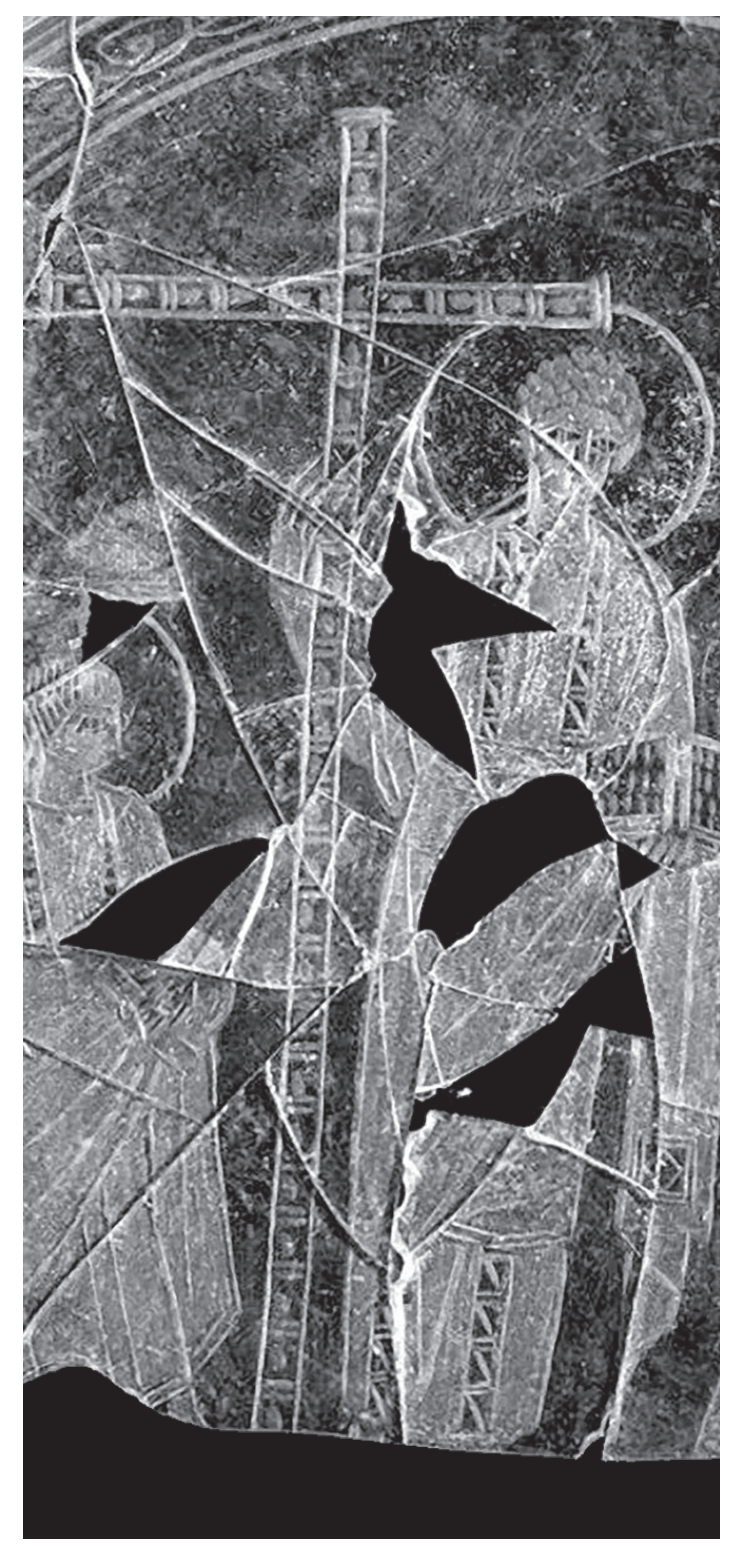

Imagen 3: Cristo en la Patena de Cástulo, en Concepción CHOCLÁN SABINA - Marcelo CASTRO, "Museo Arqueológico de LinaresMonografía de Cástulo", Boletín Arqueológico Nacional 35 (2007) 364.

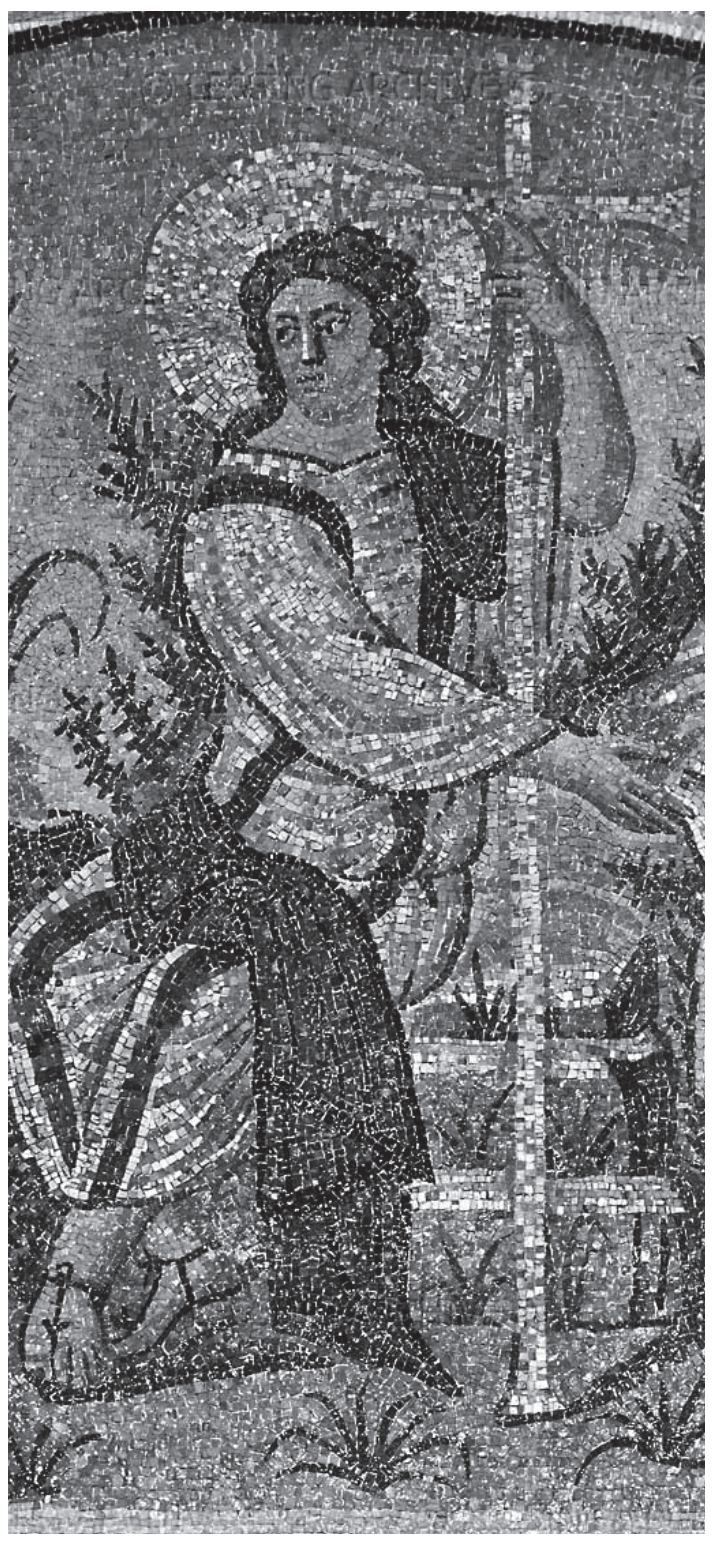

Imagen 4: Cristo en el Mausoleo de Galla Placidia (Rávena), en Lisa Onontiyoh WEST, Re-evaluating the Mausoleum of Galla Placidia. Master's Thesis: Louisiana State University, 2003. $<$ http://digitalcommons.lsu.edu/gradschool_ theses/1328/> [consultado: 20 de mayo de 2019]. 


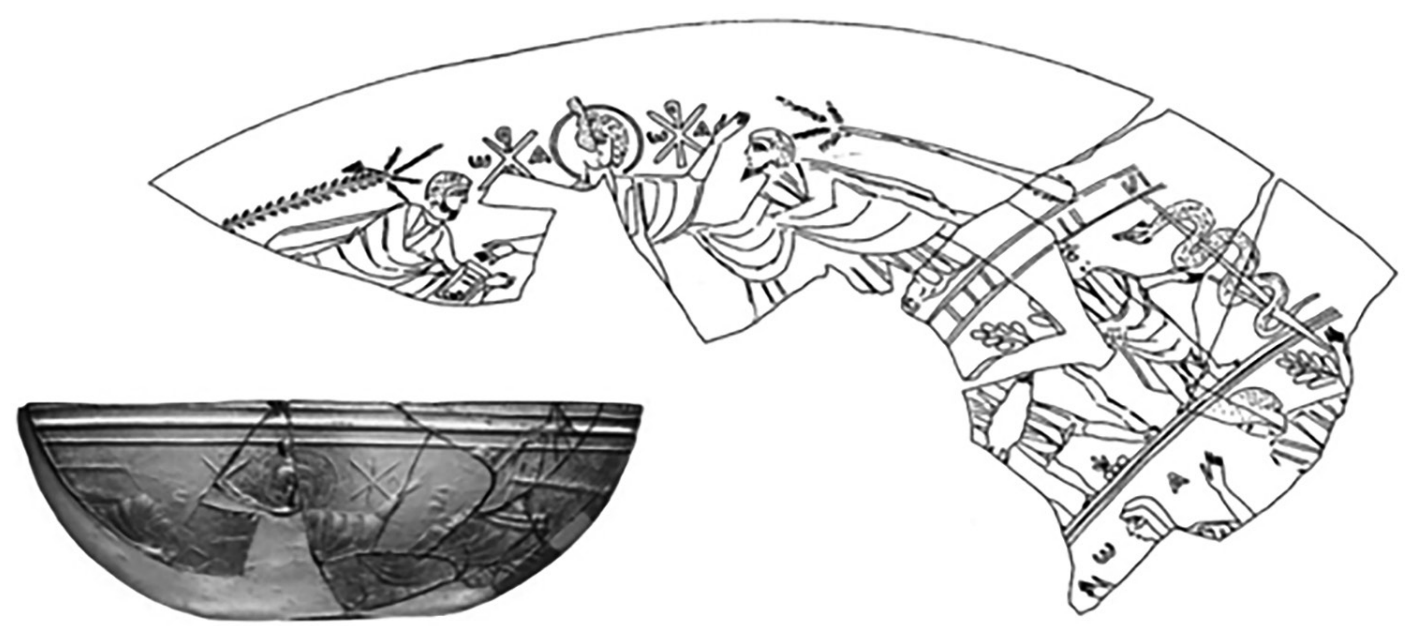

Imagen 5: Cuenco de la Almoina, en Benito GoERLICH, “El primer cristianismo en la ciudad. La figura de San Vicente Mártir", en Jorge Hermosilla Pla, La ciudad de Valencia. Historia, geografía y arte en la ciudad deValencia II; Valencia, Universitat deValencia, 2009, 276-277.

En España también se encuentra un ejemplo parecido por su representación iconográfica a la patena de Cástulo, se trata del cuenco vidriado de la Almoina (Valencia).

Este cuenco hemisférico del siglo Iv, es de una tonalidad verdosa, según la descripción de autores como Benito Goerlich. Su rica representación está compuesta por cinco escenas, en las cuales se pueden ver narraciones de temática religiosa, siendo la Traditio Legis la escena principal de las mismas. Aparece Cristo flanqueado por dos personajes ataviados a la manera helénica. Se observa cómo uno de los personajes, posiblemente san Pedro, recoge de las manos de Cristo un rollo o la Nueva Ley. ${ }^{14}$

Llama la atención que el Mesías esté flanqueado por dos crismones sobre sus brazos. La escena se completa con dos palmeras a izquierda y derecha de los personajes. La composición en sí misma parece narrar y evangelizar al mismo tiempo. Parte de la imagen del pecado original, representado por una serpiente enroscada junto a una figura masculina que recuerda las palabras de Génesis 3,1-15 ("La serpiente, el más astuto de los animales del campo que había hecho el Señor... Entonces Dios preguntó ¿Qué has hecho mujer?Y ella respondió: la serpiente me engañó y comí"). Continua con representaciones de algunos de los milagros de Cristo, como las bodas de Caná, recogidas en Juan 2,1-12 ("Hubo una boda en Caná de Galilea. La madre de Jesús y sus discípulos estaban invitados... No les queda vino, le dijo la madre a Jesús a lo que este respondió: Mi hora aún no ha llegado... Jesús dijo a los sirvientes: Llenad las tinajas de agua") y el vino fue convertido en agua, obrándose el primer milagro de

14 Cf. Benito Goerlich, "El primer cristianismo en la ciudad. La figura de San Vicente Mártir", en Jorge Hermosilla Pla, La ciudad de Valencia. Historia, geografía y arte en la ciudad de Valencia II; Valencia, Universitat de Valencia, 2009, 276-277. 
Imagen 6: Cuenco vidriado al estilo Traditio Legis. Museo de Arte de Ohio (Estados Unidos), ref. 1967.12. Galería 18

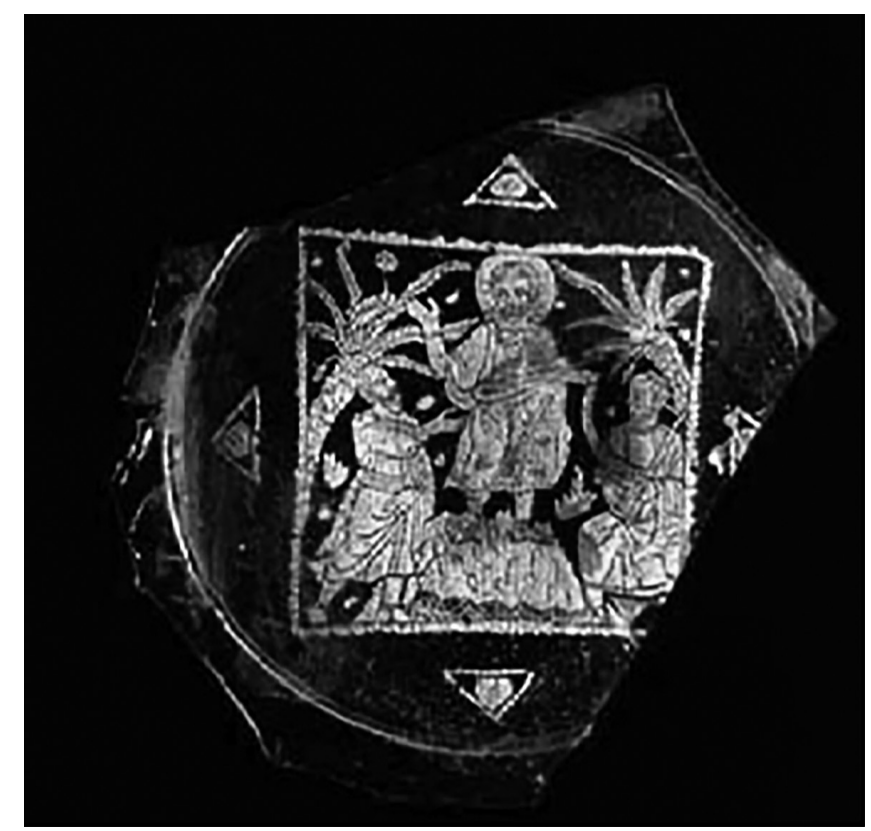

Jesús. La resurrección de Lázaro en Juan 11,1 (“Y dijo Jesús: Lázaro ha muerto, y me alegro de no haber estado allí, así tendréis un motivo para creer... Yo soy la resurrección y la vida, el que cree en mí, aunque haya muerto vivirá... Jesús oró al padre y tras esto dijo con voz potente: Lázaro, levántate y anda. El muerto salió del sepulcro"). Finalizan la composición con dos figuras orantes que no se pueden identificar con claridad con el alfa y la omega junto a sus cabezas.

Es el triunfo de Cristo Maiestas, que ha vencido al pecado y a la muerte, obrando milagros, que entrega la Nueva Ley por la que todos los bautizados pueden ser perdonados. Su poder es infinito, como se muestra en Mateo 28,18: "Jesús se acercó y les habló diciendo: Me ha sido dada toda potestad en el cielo y en la tierra".

Otro ejemplo vidriado (imagen 6) sería el que se encuentra en el Museo de Arte de Toledo (Ohio, Estados Unidos). ${ }^{15}$ Es un cuenco fragmentado de tonalidad oscura y decoración dorada que posee unas dimensiones de 12,4 cm de diámetro y $0,2 \mathrm{~cm}$ de espesor.

La imagen está enmarcada dentro de una figura cuadrangular, teniendo a su vez en sus lados cuatro figuras triangulares de pequeño tamaño con un círculo central. Cristo con nimbo, se sitúa en el centro de la escena, sobre un montículo. A su derecha parece estar san Pedro, que recoge un rollo con la inscripción: DOMINUS LEGE (M) DAT. A su izquierda se encontraría san Pablo. Los tres personajes llevan barba, están ataviados con túnica al estilo helénico y portan unas sandalias. Cabe destacar, que la figura atribuida a san Pedro lleva una cruz apoyada sobre su hombro. Enmarcan la escena dos grandes palmeras que sobresalen a izquierda y derecha.

15 Toledo Museum of Art, Art in glass, a guide to the glass collections, Toledo, Estados Unidos, 1969, 29. 
También del siglo Iv es la siguiente pieza vidriada de probable origen romano (imagen 7), en la que iconográficamente aparece Cristo flanqueado por san Pedro y san Pablo, aunque no representa iconográficamente la Traditio Legis. Tiene un diámetro de 16 centímetros, 13 en su interior, y un grosor de 0,3 centímetros. En el centro aparece representado Cristo, como si estuviese descendiendo o ascendiendo al cielo, flanqueado por dos figuras de mayores dimensiones. El Mesías tiene los brazos alzados y lleva, a izquierda y a derecha, el sol y luna con los que corona a los apóstoles. Los tres personajes imberbes aparecen vestidos con túnica, al estilo clásico.

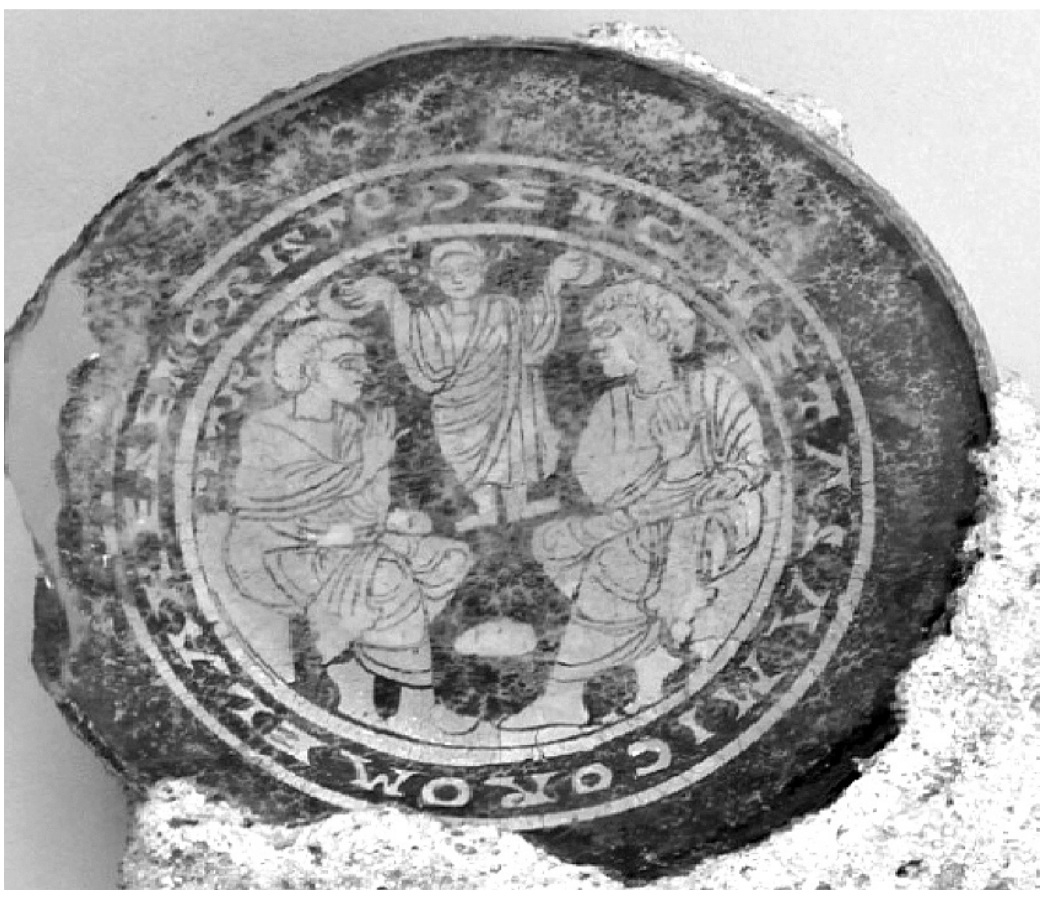

Imagen 7: Cristo coronando a San Pedro y san Pablo. Museo Metropolitano de Nueva York (Estados Unidos). Ref. 11.91.4. Galería 300. Cf. C. Louise AVErY, "The Metropolitan Museum of Art Bulletin"vol. 16 n. ${ }^{\circ} 8$ (1921) 171.

Imagen 8: Pedro y Pablo flanqueando a un crismón. Museo Metropolitano de Nueva York, ref. 16.174.3, Galería 300. Cf. C. Louise AvEry,"The Metropolitan Museum of Art Bulletin" vol. 16 n. 8 (1921) 173.

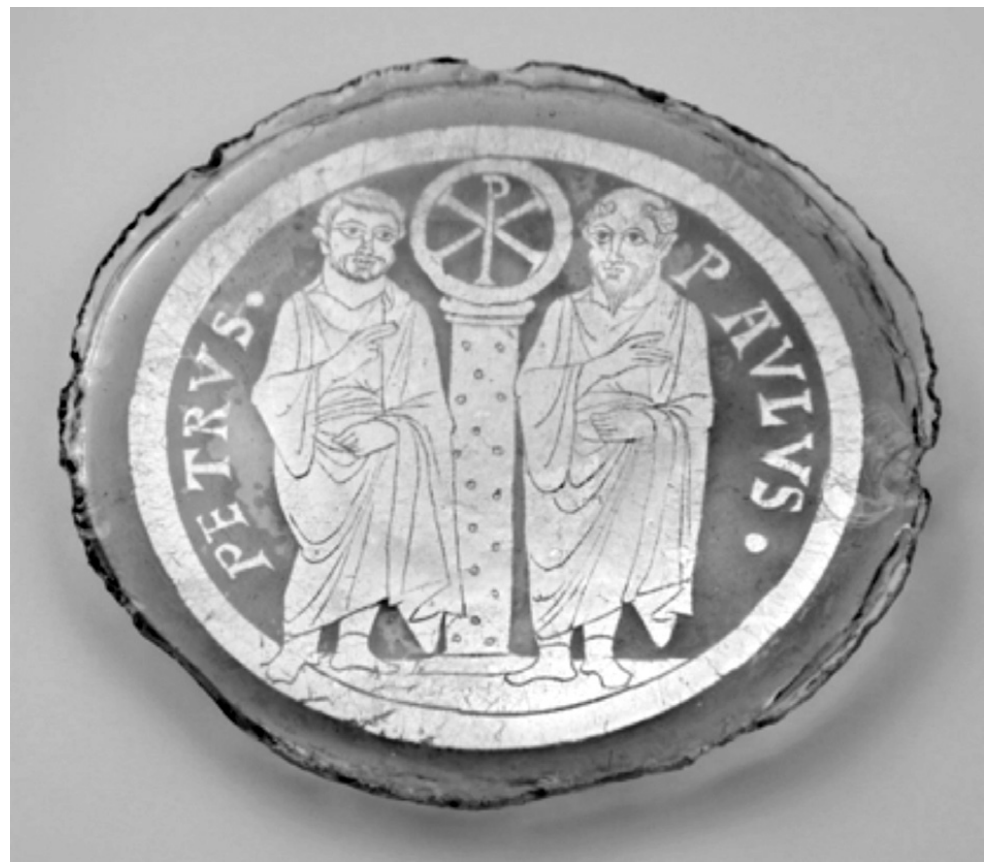


La imagen está enmarcada en un doble círculo de tonalidad dorada y en su interior, escrito en letras capitales latinas puede leerse: ELARES EN CRISTO DENGNETAS AMICORUM (gozosos en Cristo, dignos entre sus amigos/los suyos). A izquierda y derecha detrás de los personajes de mayor tamaño puede leerse: PETRUS PAVLUS.

Del siglo IV y de origen bizantino (imagen 8), esta pieza vidriada de tonalidad casi transparente y con decoración en pan de oro, tiene un diámetro de 3,7 centímetros y 0,6 centímetros de espesor. En la imagen aparecen dos personajes rodeando un crismón sobre una gran columna. Se puede leer en letras capitales latinas al lado de cada figura PETRUS y PAVLUS, respectivamente.

Ambos personajes aparecen ataviados con túnica y descalzos, con barba rizada y pelo corto. Con una mano sostienen el pliegue de la vestimenta y con la otra hacen un gesto de adoración hacia el crismón.

El siguiente ejemplo vidriado (imagen 9), con decoración en pan de oro en su interior, también se cree que es de procedencia romana y del siglo iv. Tiene un diámetro de entre 13 y 11,5 centímetro en su interior y 0,4 centímetros de grosor. En la imagen se pueden observar tres figuras de pie, vestidas con togas. Los personajes son imberbes y están rodeados de algunas flores. La escena enmarcada con un cuadro con una inscripción en letras capitales latinas: PETRUS PAULUS PEREGRINA. Parece que el jardín representa el Paraíso o el Edén. Es una imagen idílica, donde los tres personajes aparecen jóvenes, como si estuvieran disfrutando de la promesa de la resurrección y de la vida eterna junto al Mesías.

Imagen 9: Cristo con san Pedro y san Pablo en el paraíso. Museo Metropolitano de Nueva York

(Estados Unidos). Ref. 18.145.5. Galería 300.

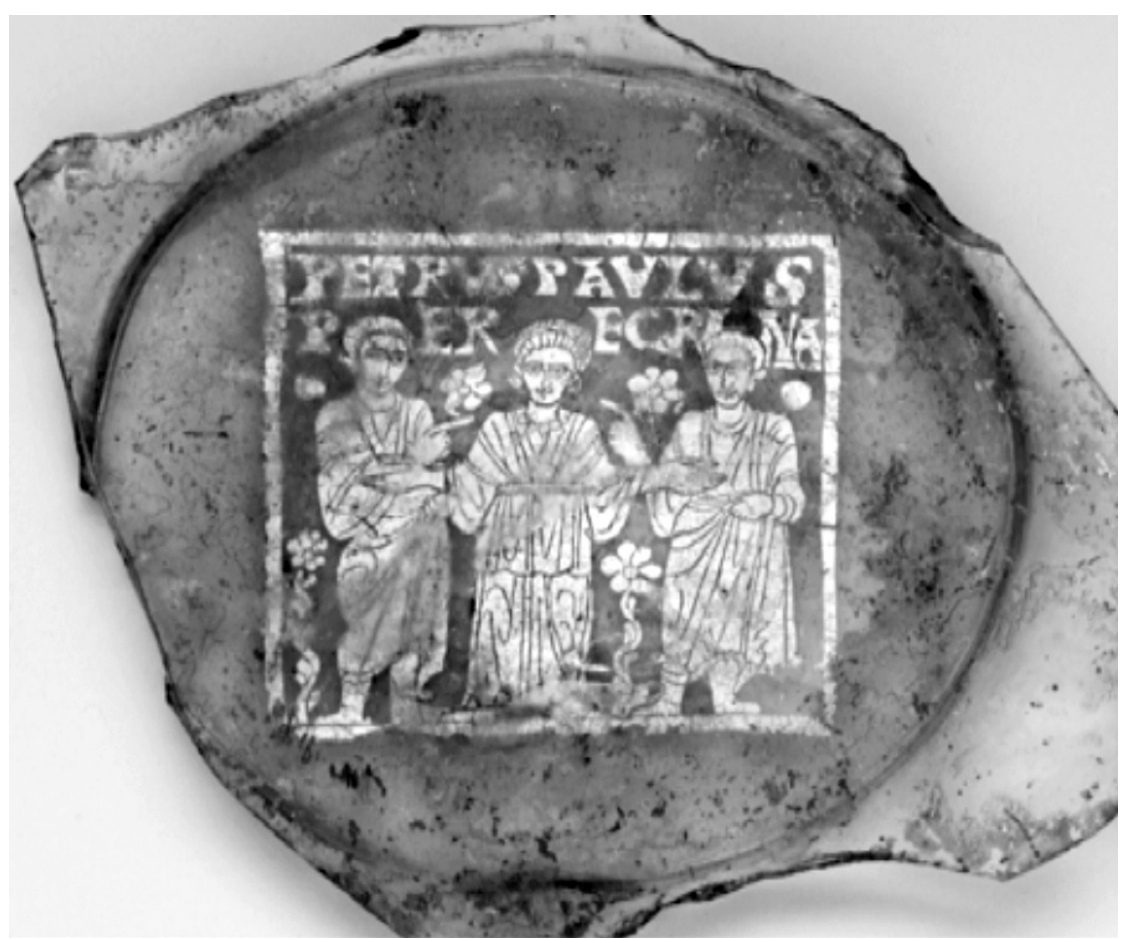




\section{CONCLUSIONES}

La arqueología clásica, en la Península Ibérica, ha centrado sus estudios en los restos arquitectónicos, cerámicos o de mosaicos, mientras que el vidrio ha sido relegado a un segundo plano. ${ }^{16} \mathrm{El}$ tono verdoso o ligeramente amarillento de los platos o cuencos bajo vidriados es algo homogéneo en el Mediterráneo occidental durante los siglos Iv y v. Ciertos cambios en la industria vidriera durante el siglo Iv harán surgir artesanos locales con nuevas formas estéticas más toscas. ${ }^{17}$

Tras el concilio de Nicea, en el año 325, y la asimilación del derecho romano por parte de la Iglesia reconocida por el emperador Constantino se empieza a definir los elementos artísticos del nuevo orden cristiano. Presentará la nueva imagen de Cristo como emperador de forma que los modelos clásicos siguieron siendo imitados pero acorde a la nueva religión. ${ }^{18}$ La Traditio Legis representa claramente el primado de Pedro en la Iglesia y a esta como continuadora de las enseñanzas de Cristo. ${ }^{19}$ En la imagen 7 se puede observar cómo no solo se representa la Traditio Legis sino que se encuentra la utilización de Cristo junto a san Pedro y san Pablo. De igual modo ocurre en la imagen 8, donde Cristo aparece bajo la iconografía de un crismón, plasmando la imagen descrita en Apocalipsis 21,6 ("Yo soy el alfa y la omega, el principio y el fin"). Es muy significativa la asimilación por parte de la iconografía cristiana de la representación de Cristo en el crismón, como una imagen cargada de simbolismo que hunde sus raíces en la tradición griega.

La gran promesa del cristianismo, la vida eterna y su disfrute en el paraíso, viene icónicamente representada en la imagen 9, donde se puede observar a Cristo junto a san Pedro y a san Pablo en un jardín. Atendiendo al contexto histórico, esta representación responde a la doctrina que enseña la Iglesia. Numerosos estudios apuntan a que los platos de vidrio y vidriados eran de fabricación romana y por tanto de importación. Todo esto hace pensar que puede que se estuvieran marcando unas pautas iconográficas que reforzarían el poder del papa, como primado de toda la Iglesia al ser continuador legítimo de san Pedro.

Muy revelador es el evangelio de san Mateo, donde parece que se fijan las bases del poder que la Traditio Legis intenta transmitir a san Pedro: "Y yo a mi vez te digo que tú eres Pedro y sobre esta piedra edificaré mi Iglesia" (Mateo 16,18).

Por último, llama la atención su estética. Estos utensilios apenas tienen decoración externa, solo el cuenco de la Almoina posee algunos crismones en su exterior, limitándose a la decoración iconográfica en el fondo del cuenco. La

16 Cf. Dahí Elena, “Vidrios", 219.

17 Cf. María Dolores Sánchez De Prado, “La vajilla de vidrio durante la Antigüedad Tardía en el Conventus Carthaginensis", BSAA Arqueología 75 (2009) 182-196.

18 Cf. Martínez Gázquez, "Memoria de la Maiestas Domini", 39.

19 Cf. Santiago Manzarbeitia Valle, "San Pablo", Revista Digital de Iconografía Medieval vol. 7 n. ${ }^{\circ} 14$ (2015) 46. 
liturgia cristiana permite conocer que estos recipientes eran utilizados por los sacerdotes en el momento de oficiar la eucaristía. Si esta afirmación es correcta ¿llegarían los fieles a ver con detalle y claramente estas imágenes? El altar es el corazón del edificio eucarístico, es el martyrium de Cristo, el núcleo principal sobre el cual se articula toda la edificación cristiana. Sus programas iconográficos y decorativos están orientados a su sacralidad. ${ }^{20}$ La primera iconografía cristiana está llena de símbolos que intentan explicar a los fieles el mensaje de salvación de Jesús, por lo que se puede ver en los ejemplos anteriores a Cristo Salvador junto a san Pedro y san Pablo en el Paraíso o a Cristo como Nuevo Legislador o Emperador, entregando la Nueva Ley a sus discípulos.

Las representaciones de Cristo respondían a un propósito simbólico y teológico, de ahí que sus imágenes fueran utilizadas para la enseñanza de una sociedad en su gran mayoría iletrada. La Traditio Legis guarda grandes semejanzas con el Pantocrator románico, en el que aparece Cristo en majestad con un carácter hierático y de frontalidad, siguiendo el modelo clásico paleocristiano en cuanto al uso de la túnica y la utilización de sandalias como se puede observar en las imágenes 6 y 9. También se continúa representando al Mesías con las letras A y $\Omega$ a izquierda y derecha, dando continuidad al mensaje de Cristo como principio y fin de todo lo creado. Por otra parte, destaca el libro que porta, generalmente abierto y que se identificó con la Nueva Ley durante los primeros años del cristianismo, aunque en la representación del Pantocrator es visto como el libro de la vida, que puede aparecer tanto abierto como cerrado ya que solo el Cordero puede abrirlo. ${ }^{21}$

Las patenas, al igual que los cálices y el resto de los elementos que componen el altar cristiano son, junto el sagrario, los utensilios más sagrados en el rito cristiano. Siguiendo la premisa de que la posesión de estos materiales vidrios no era algo asequible para todo el mundo ya que, en su mayoría, eran de fabricación romana, y por tanto de importación, se podría llegar a entender el gran valor que se les dio a estos platos decorados con el esquema iconográfico de la Traditio Legis o de Cristo junto a san Pedro y san Pablo.

Los avatares históricos ocurridos a partir del siglo v, con la fragmentación del imperio romano y la creación de nuevos reinos germanos propiciaron el descenso de la fabricación de platos vidriados para la eucaristía y su casi total desaparición. Esto, unido a la fragilidad del material ha dado lugar a una escasa conservación de estos ejemplares vidriados.

20 Cristina Godor Fernández, Arqueología y liturgia. Iglesias hispánicas (siglos IV al viII), Barcelona, Universitat de Barcelona, 1995, 49.

21 Cf. Helena Carvajal GonzÁlez,"El libro de la vida”, Revista Digital de Iconografía Medieval, vol. 6, n. ${ }^{\circ} 12$ (2014) 19. 